\title{
Photoacoustic Spectroscopy Applied to the Study of Bone Consolidation In fractures
}

\author{
P. A. Lomeí Mejia ${ }^{1, a}$, G. Urriolagoitía ${ }^{2}$, J.L. Jiménez Pérez ${ }^{3, b}$, \\ L. H. Hernández Gomez ${ }^{2}$, H. Lecona Butron ${ }^{1}$, A. Cruz Orea ${ }^{4}$ \\ ${ }^{1}$ Centro Nacional de Rehabilitación y Ortopedia, \\ Calz. México-Xochimilco \# 289, Col. Arenal de Guadalupe c.p. 14389-México D.F. \\ ${ }^{2}$ IPN SEPI-ESIME, Departamento de Mecánica, Zacatenco, México, D.F. \\ ${ }^{3}$ CICATA-IPN, Legaria 694, Col. Irrigación, 11500 México D.F., México \\ ${ }^{4}$ Departamento de Física, CINVESTAV-IPN, A.P. 14-740, 07300 México D.F., México. \\ apalm7@hotmail.com, ${ }^{\mathrm{b}}$ iimenezp@fis.cinvestav.mx.
}

Keywords: Osteogenesis; Osteotomy; Photoacustic effect

\begin{abstract}
By using photoacoustic (PA) spectroscopy it was performed a study about bone consolidation in fractures. It was obtained the optical absorption spectra of callus of male rat fractured bones at different consolidation times. From these spectra it was possible to observe the presence of alkaline phosphatase through their absorption peaks which were compared with characteristic peaks reported in the literature for this phosphatase. In this study we showed that alkaline phosphatase could be considered as an indicator of the repair process of bone fractures
\end{abstract}

\section{Introduction}

The bone consolidation is one of the big concerns in medicine, mainly with people of advanced age, with some pathology, as beging metabolic or vascular types among other causes of the retard of bone healing. In some cases it is possible to think in a treatment that allows to accelerate the osteogenesys, nonetheless, there are few non intrusive methods available (laser, magnetic and electric fields etc.) and in many cases are natures (there is not an external treatment).

For the case of natural bone consolidation the integration of bone with tissue and corporal liquids create a bone callus, as time pass, modifying all their chemical, physical and biological properties of the tissue-bone system in the fracture. An alternative way to know the changes during bone consolidation could be done by photoacoustic (PA) analysis of fracture bone callus, at differents times of bone consolidation, where it would be possible to obtain the optical absorption spectra at differents consolidation estages. Through our PA analysis it was possible to verify the presence of alkaline phosphatase, the main substance which cause the bone consolidation.

The alkaline phosphatase (AP) is an enzimatic set, mainly founded in the liver (ALP-1 izoenzime) and bone (ALP-2 izoenzime). There are also small quantities produced by intestine (ALP-3 izoenzime), placenta and kidney. The level of phosphatase in blood gives a measurement of the released phosphatase from the mentioned tissues above. As its name indicates, this enzime is associated with an alkaline $\mathrm{pH}$ (aproximately 10), and then the enzime itself is inactive in blood. The $\mathrm{AP}$ acts for defold of phosphorous, creating an alkaline $\mathrm{pH}$. The optimum level of AP depends on the age, then an adolecent has a higher level of AP than an adult whose bone growing have finished [15], [8].

One important feature of photoacoustic spectroscopy (PAS) technique is that scattered light does not disturb the measurements significantly, so that the optical properties of biological sample can be investigated easily and directly with this technique. The use of PAS to measure optical absorption spectra has advantages over the usual transmission measurements in which the sample needs to be 
prepared to have a good quality surfaces, and also because with PA measurements we can avoid the optical interference effects to obtain well resolved optical absorption spectra [6]. This study is focousing on natural bone consolidation due to the complex mechanisms that occurs during the consolidation process. In this paper we report the optical absorption spectra of AP at different consolidation periods of fractured rat bones.

\section{Experimental methods}

For this study we used twenty Wistar male rats, with $700 \mathrm{gr}$ average weight. The care and feeding were done in agreement with Mexican official standard NOM(Z0066-98). A pentobarbital sodic dose $(50 \mathrm{mg} / \mathrm{Kg})$ was intraperitonally applied, $5 \mathrm{~mm}$ below of apofisis xifoide. It was perfomed a 3 to $5 \mathrm{~mm}$ encision in medial craneum, in the tibia distal third. It was separed the superficial and deep faces with Zen Miller separaters. After this it was used a jeweller fretsaw to make the fracture outline, taking care of don't damage other tissues. To stabilize the fracture it was placed a Kirschner wire $(0.035 \mathrm{~mm}$ stainless steel wire). The final stage in this process was to stitch layer by layer, beginning by periostis, muscle and finally the skin. Later it was cleaned the injury with a saline solution and the rats were placed in polycarbonate cages, with steel lid and it was allowed them free movement. Two rats were sacrified each six days and "antero posterior" radiographies were taken of them. In our study we take into account only the right tibias of the sacrified rats also the soft tissues were removed, after this the tibias were dried in a natural way. From the fracture bones a fragment of the formed callus was removed (approximately $15 \mathrm{~mm}^{2}$ area) by using a fretsaw.

The optical absorption spectra of the removed fracture bones, were obtained in the range of 350 to $850 \mathrm{~nm}$ by using a home-made PA spectrometer as showed in Fig. 1. The experimental setup consisted of a $1000 \mathrm{~W}$ Xenon lamp (Oriel), a variable frequency mechanical chopper, set at $17 \mathrm{~Hz}$, a monochromator, and an air-filled brass cell with a condenser microphone. The PA signal from the microphone provided the input to the signal channel lock-in amplifier (SR-850) which is interfaced to a personal computer, displaying the wavelength-dependent signal amplitude and phase simultaneously. In order to take into account the Xe lamp emission spectrum, the PA signal was normalized to the signal obtained from charcoal powder.

\section{Results and discussions}

Figure 2, shows the PA optical absorption spectra of dry fractured bones of the Wister male rat. These spectra, in the range of 350 to $850 \mathrm{~nm}$, correspond to bones with blood and bone callus. For these experiments twenty rats were sacrificed at different bone consolidation times (from 6 to 50 days). It was observed that PA optical absorption spectra decrease in amplitudes as the consolidation time increases. The characteristic absorption peaks of hemoglobin $(430$ and $530 \mathrm{~nm})$ are observed $[9,10]$. In this figure the spectrum corresponding to normal bone, without bone callus but with blood, is denoted by a solid line. The PA differential spectra between the optical absorption spectra of bones (at different consolidation times as they are shown in Fig. 2) and the spectrum 


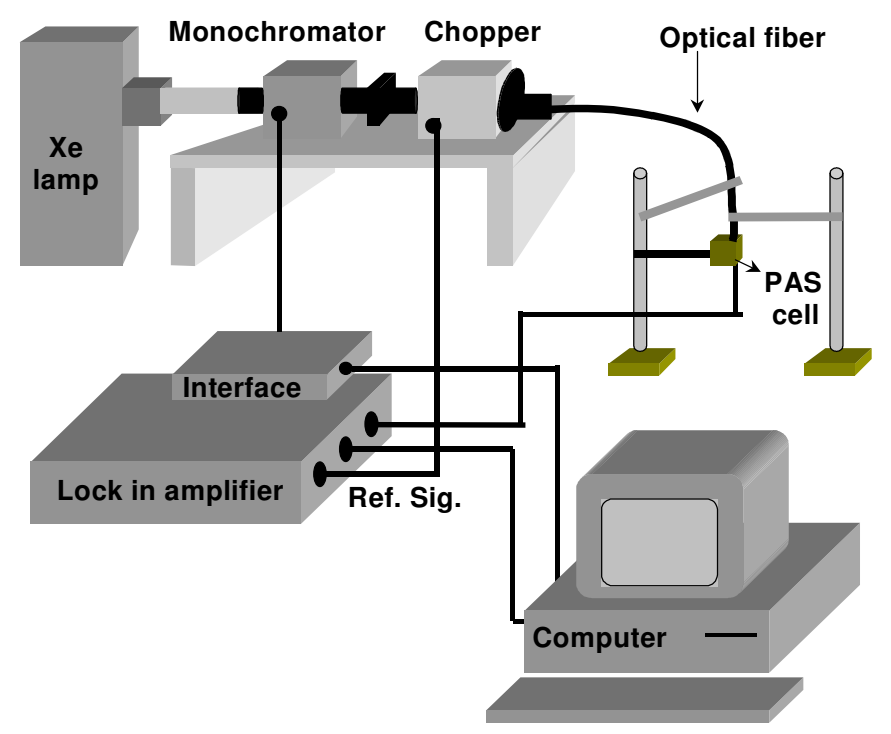

Fig. 1. Experimental set-up used in Photoacoustic spectroscopy.

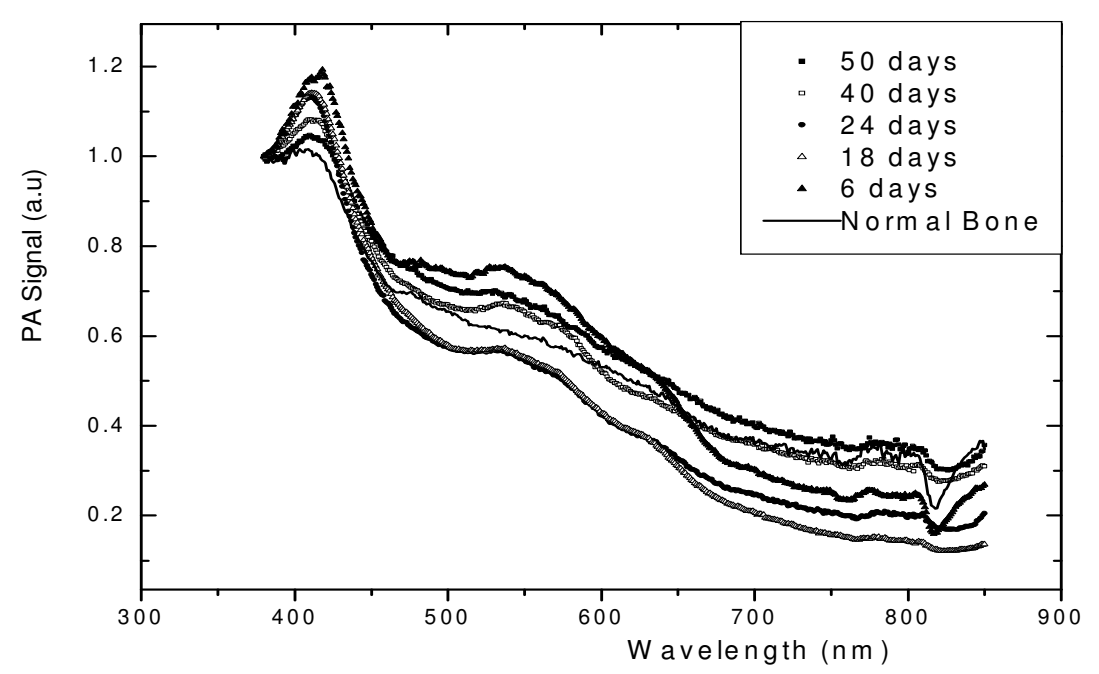

Fig. 2. Photoacoustic absorption spectra of dry bones with bone blood and callus at different consolidation times. In these spectra it is possible to see the characteristic absorption peaks of hemoglobin at 430 and $530 \mathrm{~nm}$.

corresponding to normal bone with blood was done. To this PA differential spectra were subtracted the PA spectrum obtained from blood in order to have a callus spectra which is showed in Fig.3. In these PA callus spectra it is possible to see a maximum absorption band in the range of 404 to 412 $\mathrm{nm}$, which corresponds to absorption range of p-Nitrophenylphosphatase which presence is characteristic in rat fractured bones [7]. In this figure it is possible to observe the same behaviour as in Fig. 2 but without the presence of blood. Here the absorption band corresponding to this alkaline phosphatase decrease as the callus grows in the consolation time. In Fig. 4 we show the PA average values, corresponding in Fig. 3 to the PA values in the range of 404 to $412 \mathrm{~nm}$, presented as a function of consolidation time ( 0 to 50 day after fractured). Each point in this figure corresponds to three samples. As it can be seen these values decrease as a function of time in a three-cornered way. This behaviour indicates that alkaline phosphatase concentration decrease as the bone is consolidating (and the bone callus is growing). These results are in agreement with the evolution of serum alkaline phosphatase activities reported for patients with fractures [7]. 


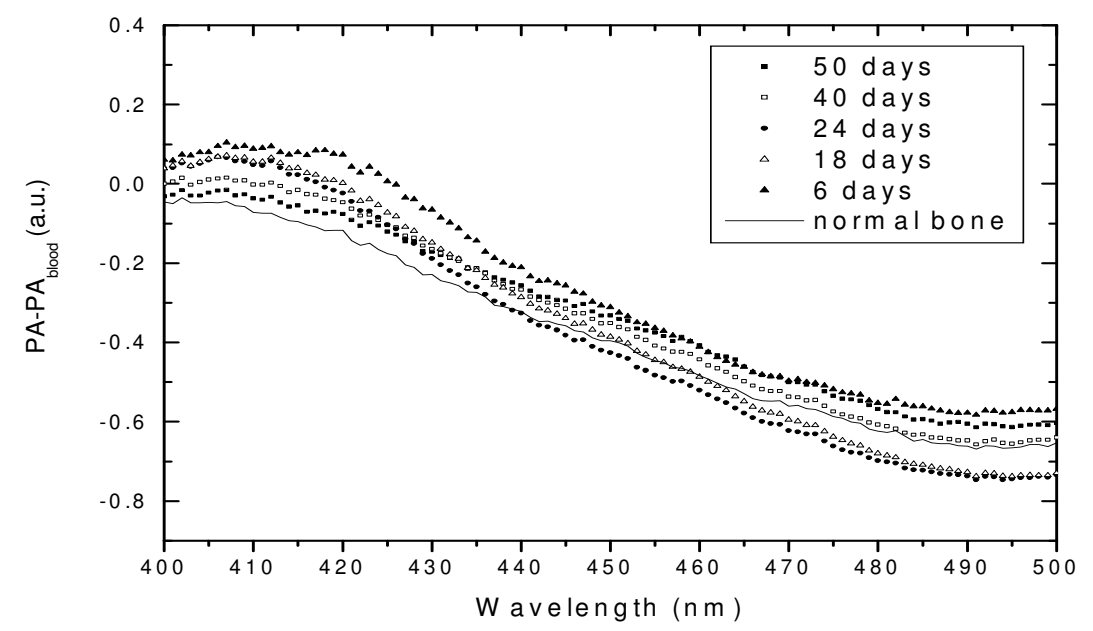

Fig. 3. Differential Photoacoustic absorption spectra of bone callus at different consolidation times. In these spectra it is possible to see a maximum absorption band in the range of 404-412 nm, which corresponds to absorption range of p-Nitrophenylphosphatase. This phosphatase is characteristic in fractured rat bones [7].

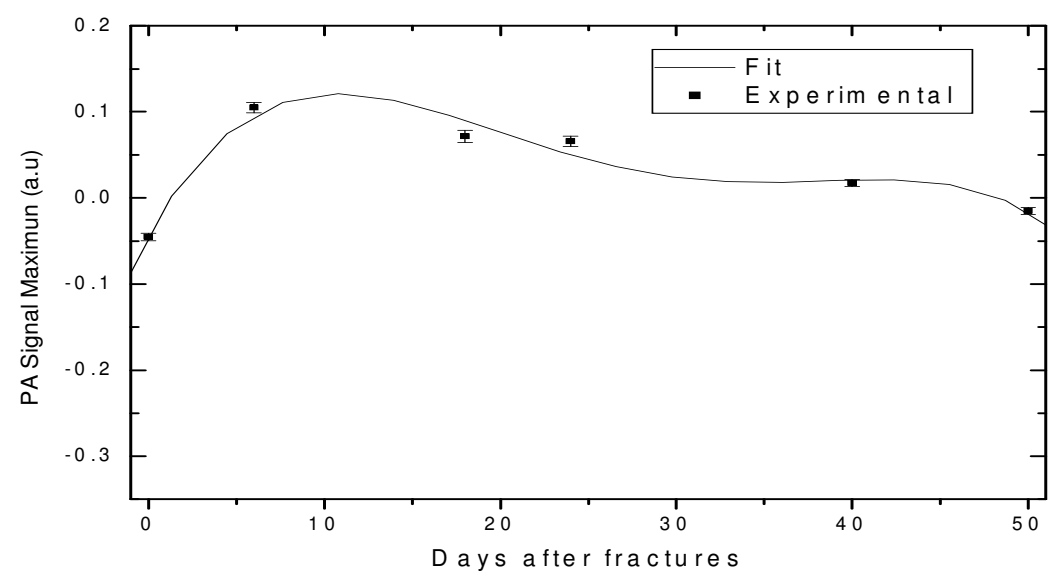

Fig. 4. We show the average values of PA signal at 404-412 $\mathrm{nm}$ bands (as presented in Fig.3) as a function of the consolidation time.

\section{Summary}

It was performed a study about consolidation of fractured tibia bones of Wister rats. By obtaining PA optical absorption spectra of these fractured bones, in which a bone callus is formed, it was possible to verify the presence, between other components, of alkaline phosphatase at different concentrations, by identifying its characteristic optical absorption band as a function of at different bone consolidation times.

\section{Acknowledgements}

We gratefully acknowledge the technical support of Ing. M. Guerrero, one of the authors (J.L. Jiménez Pérez) wants to thank the partial financial support received from Conacyt - México, CGPI and COFAA - IPN México.

\section{References}

[1] T. Diamond, M. Lindenberg, Aust. Fam. Physician Vol.31(8) (2002), p. 751

[2] A.K. Vocke-Hell, A. Schmid, J. Pediatr. Orthop. B, Vol. 10(2) (2001) p.138.

[3] C. Simonelli, J. Am. Med. Womens Assoc. Vol. 55(4) (2000), p. 228. 
[4] K.H. Cho, B.H. Park, K.M., Yeon, Ultrasound CTMR Vol. 21(3) (2000), p. 214

[5] M. Bohnsack, F. Gosse., O. Ruhmann, K. Wenger, J. Spinal Disord. Vol. 21(6) (1999), p. 481

[6] A. Rosencwaig, A. Gersho, J. Appl. Phys Vol. 47 (1976), p. 64

[7] R. B. McComb, G. N. Bower, Jr. and S. Posen, Alkaline Phosphatase (Plenum Press. New York and London. 1979).

[8] Laser Therapy Vol. 6 (1994), p. 16

[9] I.G.F. Freitas, V. Baranauskas, M.A. Cruz-Hofling, Appl. Surf. Sci. Vol. 154-155 (2000), p. 548

[9] W. Hoppe, W. Lohmann, H. Markl, H. Ziegler, Biophysics (Springer-Verlag, Berlin Heidelberg New York Tokyo, 1983).

[10] A. Rosencwaig, Science Vol. 18 (1973), p. 657 